\title{
Genetic differentiation of Anopheles gambiae populations from East and West Africa: comparison of microsatellite and allozyme loci
}

\author{
TOVI LEHMANN* $\uparrow$, WILLIAM A. HAWLEY $\uparrow \ddagger$ LUNA KAMAU $\ddagger$, DIDIER FONTENILLE§, \\ FREDERIC SIMARD§ \& FRANK H. COLLINS + I \\ †Division of Parasitic Diseases, Centers for Disease Control and Prevention, MS F22, 4770 Buford Highway, \\ Chamblee, GA 30341, U.S.A., łKenya Medical Research Institute, Clinical Research Centre, Nairobi, \\ Kenya, §Laboratoire ORSTOM de Zoologie Medicale, Institut Pasteur, BP 220, Dakar, Senegal and १Department of \\ Biology, Emory University, At/anta, GA 30322, U.S.A.
}

\begin{abstract}
Genetic variation of Anopheles gambiae was analysed to assess interpopulation divergence over a $6000 \mathrm{~km}$ distance using short tandem repeat (microsatellite) loci and allozyme loci. Differentiation of populations from Kenya and Senegal measured by allele length variation at five microsatellite loci was compared with estimates calculated from published data on six allozyme loci (Miles, 1978). The average Wright's $F_{\text {ST }}$ of microsatellite loci $(0.016)$ was lower than that of allozymes (0.036). Slatkin's $R_{\mathrm{ST}}$ values for microsatellite loci were generally higher than their $F_{\mathrm{ST}}$ values, but the average $R_{\mathrm{ST}}$ value was virtually identical $(0.036)$ to the average allozyme $F_{\mathrm{ST}}$. These low estimates of differentiation correspond to an effective migration index $(\mathrm{Nm})$ larger than 3, suggesting that gene flow across the continent is only weakly restricted. Polymorphism of microsatellite loci was significantly higher than that of allozymes, probably because the former experience considerably higher mutation rates. That microsatellite loci did not measure greater interpopulation divergence than allozyme loci suggested constraints on microsatellite evolution. Alternatively, extensive mosquito dispersal, aided by human transportation during the last century, better explains the low differentiation and the similarity of estimates derived from both types of genetic markers.
\end{abstract}

Keywords: allozymes, Anopheles gambiae, gene flow, microsatellites, population genetic structure, population genetics.

\section{Introduction}

In sub-Saharan Africa Anopheles gambiae is the principal vector of human malaria, a disease which continues to inflict immense misery despite substantial efforts to bring it under control. An understanding of the genetic structure of $A$. gambiae populations is critical in evaluating the possibility of genetic manipulation of this species to block malaria transmission (e.g. Collins \& Besansky, 1994; Crampton et al., 1994). Moreover, such understanding could also aid control based on currently available technology, such as in the management of insecticide resistance.

\footnotetext{
*Correspondence.
}

Microsatellite loci have been described as powerful markers for measuring intraspecies differentiation because of their high polymorphism, codominance, abundance throughout the genome, and relative ease of scoring (Bowcock et al., 1994; Estoup et al., 1995). A microsatellite survey in $A$. gambiae (Lanzaro et al., 1995) demonstrated the above features and concluded that microsatellite loci are superior to allozymes for studies of population structure. Currently several groups are using microsatellite loci to assess gene flow and related phenomena in the A. gambiae complex of species. The forces that shape allele composition at such loci are poorly understood, however (Edwards et al., 1992; Di Rienzo et al., 1994; FitzSimmons et al., 1995; Garza et al., 1995), and some evidence suggests that these forces include biased mutation rates (Garza et 
al., 1995) and/or selection acting on allele size (Epplen et al., 1993). If such forces strongly influence allele composition at these loci, estimates of differentiation between populations and rates of gene flow will be misleading, because they are derived on the basis of genetic drift, migration, and random mutation as the main forces in operation.

Using five polymorphic microsatellite loci, we measured differentiation between populations of $A$. gambiae from Kenya and Senegal that represent two geographical extremes $(6000 \mathrm{~km})$ in the range of this species. Assuming that gene flow is restricted by distance, genetic differentiation between these populations would be expected to be near the maximum possible for the species. Additionally, we compared differentiation based on microsatellite loci, using both Wright's $F_{\mathrm{ST}}$ and Slatkin's $R_{\mathrm{ST}}$, to differentiation based on the allozyme data (Miles, 1978) using Wright's $F_{\mathrm{ST}}$ derived from populations in Kenya and The Gambia. The rationale for this comparison was to evaluate the possibility that constraints on microsatellite loci such as biased mutation rates or selection on allele size could yield lower estimates of population differentiation than those based on allozyme data.

\section{Materials and methods}

\section{Study sites}

The Asembo Bay area in western Kenya is located on the northern shores of Lake Victoria. It is a relatively flat, densely populated landscape, traversed by semipermanent streams. During the major rainy season (April to July), many mosquito breeding sites are available. Mosquito populations are much reduced during the dry season, when larval breeding sites are scarce. The village of Barkedji in north Senegal is located in the Sahelian region, and A. gambiae can be found only during the June to December rainy season. In both sites, mosquitoes were collected from houses less than $2 \mathrm{~km}$ apart to minimize the possibility of sampling members of different demes.

\section{Mosquito collection}

In Kenya, mosquitoes were aspirated at dawn from bed nets hung the previous evening over the beds of sleeping volunteers. The nets were hung in a manner to leave a space for the mosquitoes to enter. Thus, samples consisted of blood-fed and blood-seeking females. In Senegal, mosquitoes were aspirated after landing on human volunteers or collected from the floor after spraying the interior of houses with pyrethrum insecticide early in the morning. Collections were carried out in Kenya between 28 June and 6 July 1994 and in Senegal on 5-6 October 1994. Only the savanna cytotype of $A$. gambiae (Coluzzi et al., 1985; Fontenille, unpublished data) and $A$. arabiensis of the $A$. gambiae complex, were present in both study sites. Only $A$. gambiae were included in the analysis, however, after species identification (Scott et al., 1993).

\section{DNA extraction and genotype scoring}

DNA from individual specimens (or parts of a specimen) was extracted as described by Collins et al. (1987) and resuspended in water or TE buffer (Sambrook et al., 1989). Loci 33C1, 29C1, 1D1 and $2 A 1$ were identified in cloned $A$. gambiae genes (Table 1). Locus $33 \mathrm{Cl}$ is from the dopa decarboxylase $(D d c)$ gene (P. Romans, unpublished data), $29 C 1$ is from the xanthine dehydrogenase gene (F. Collins, unpublished data), $1 D 1$ is from the actin1D gene (Salazar et al., 1993), and $2 A 1$ is from the white gene (Besansky et al., 1995). Locus $A G 2 H 46$ was isolated from an $A$. gambiae chromosome divisionspecific library (Zheng et al., 1991) by probing with a labelled GT-repeat oligonucleotide. Microsatellite alleles were PCR amplified and viewed by autoradiography using incorporation of alpha- ${ }^{33} \mathrm{P}$ dATP (Amersham) into the PCR product or using a primer end-labelled with gamma- ${ }^{33} \mathrm{P}$ dATP (Dupont). Both techniques provided identical results. Standard PCR in $20 \mu \mathrm{L}$ reaction volume was run in a Perkin-Elmer 9600 thermal cycler. For incorporation of radiolabelled dATP, a mixture containing $0.2 \mathrm{~mm}$ each of dGTP, dCTP, dTTP; $0.05 \mathrm{~mm}$ of dATP (Perkin-Elmer) and $0.4 \mu \mathrm{L}$ of alpha $-{ }^{33} \mathrm{P}$ dATP at $1000-3000 \mathrm{Ci} / \mathrm{mmol} ; 5 \mathrm{ng} / \mu \mathrm{L}$ of each primer (approx. 15 pmol); $1 \times$ reaction buffer (Boehringer Mannheim); and 0.035 units of Taq polymerase (Boehringer Mannheim) was used. For PCR reactions with one end-labelled primer, all dNTP concentrations were $0.2 \mathrm{~mm}, 2$ pmol radiolabelled primer with $8 \mathrm{pmol}$ of the same primer, which was not radiolabelled, $10 \mathrm{pmol}$ of the complementary primer and the other components unchanged. An equivalent of $1 / 100$ or less of genomic DNA extracted from a whole mosquito was used. PCR conditions were: denaturation at $94^{\circ} \mathrm{C}$ for $5 \mathrm{~min}$, followed by 30 cycles consisting of $94^{\circ} \mathrm{C}$ for $25 \mathrm{~s}$, $55^{\circ} \mathrm{C}$ for $28 \mathrm{~s}$, and $72^{\circ} \mathrm{C}$ for $30 \mathrm{~s}$. The last elongation step was at $72^{\circ} \mathrm{C}$ for $5 \mathrm{~min}$. The PCR product was mixed (3:2) with formamide stop solution (Amersham), denatured at $94^{\circ} \mathrm{C}$ for $5 \mathrm{~min}$ before loading 
Table 1 Microsatellite loci in Anopheles gambiae: cytological location, repeat sequence and primer sequences

\begin{tabular}{llll}
\hline Locus & $\begin{array}{l}\text { Cytol. } \\
\text { Location* }\end{array}$ & Repeat & Primers $\dagger$ \\
\hline$A G 2 H 46$ & IIR:7A & GT & $\begin{array}{l}\text { CGC CCA TAG ACA ACG AAA GG } \\
\text { TGT ACA GCT GCA GAA CGA GC } \\
\text { CAA AGA AAG CGC CCA TAG AC }\end{array}$ \\
& & & $\begin{array}{l}\text { CGC TGT GTT TTC GTC TTG TA } \\
\text { TTG CGC AAC AAA AGC CCA CG }\end{array}$ \\
$29 C 1$ & IIIR:33C & AGC & $\begin{array}{l}\text { ATG AAA CAC CAC GCT CTC GG } \\
\text { ATG TTC CAG AGA CGA CCC AT }\end{array}$ \\
$1 D 1$ & IIIR:29C & TGA & TGT TGC CGG TTT GTT GCT GA \\
$2 A 1$ & X:1D & CCA & $\begin{array}{l}\text { TAA TGG TCC CAA ATC GTT GC } \\
\text { GTT ATC CAC TGC GCA TCA TG }\end{array}$ \\
& X:2A & 10/6 & GAA TTC GTT TAG AGT CTT TC \\
& & bases & GTA TAC AGG CCT TTG TTT CC
\end{tabular}

*The cytological position of each locus was determined by polytene chromosome in situ hybridization (Kumar \& Collins, 1993).

$\dagger$ For locus $A G 2 H 46$ the upper pair refers to the original primers and the lower pair to alternative primers (see Materials and methods).

$3 \mu \mathrm{L}$ of the mixture onto a 6 per cent acrylamide, $7 \mathrm{M}$ urea sequencing gel (Life Technologies) in parallel to a 2-lane-ladder standard, which was loaded every 10-20 lanes. The standard, constructed by sequencing an AT-rich region of $A$. gambiae mtDNA with the dideoxy terminators ddA and ddT (Beard et al., 1993), allowed exact determination of allele size. Autoradiographs of gels, developed after overnight exposure, were visually inspected and allele size was determined. Alleles were distinguished from occasional artefacts by intensity and size. These criteria were tested by scoring the alleles at loci $1 D 1$ and $A G 2 H 46$ in laboratory-reared progeny of parent mosquitoes with known genotypes. All scored genotypes were in complete concordance with the genotypes expected from the test crosses.

At locus $A G 2 H 46$, no PCR product was visible in repeated reactions for approx. 5 per cent of the specimens that were scored successfully for other loci. Using alternative primers, which flank the sites of the original primers (Table 1), PCR products were obtained. Subsequent sequencing revealed a mutation in one of the original primer annealing regions. For this locus $2 / 3$ of the homozygotes scored with the original primers were found to be heterozygotes when PCR amplification was carried out with the alternative primers. No 'hidden' heterozygotes were found in the other microsatellite loci using alternative primers.

\section{Allozyme data}

To identify allozyme alleles that could be used to identify the different cryptic species in the $A$. gambiae complex, Miles (1978) examined variation at 18 loci from $A$. gambiae complex populations from different parts of Africa. Allele frequency data based on sample sizes larger than six mosquitoes were summarized only for the loci alpha-naphthyl acetate esterases (EST-1, EST-2, EST-3), octanol dehydrogenase $(O D H)$ and phosphoglucomutases (PGM-1, PGM-2). These data for the populations from Kenya (Chulaimbo) and Gambia (Mandinari, having the largest sample size) were used. Additional analyses including samples from East, West, and Central Africa were carried out to evaluate the consistency of these results (see Discussion). We have assumed that the population structure of $A$. gambiae across the continent has not changed significantly between the time of Miles's study and the present.

\section{Data analysis}

Goodness of fit tests of genotype distributions with Hardy-Weinberg expectations in each population were performed for each microsatellite locus, after pooling rare alleles to achieve expected values per cell higher than two. Because genotype data were not available for the published allozyme data, analy- 
sis was carried out on allele frequencies, assuming random mating in each population. $F$-statistics were calculated based on Wright (1978) for microsatellite and allozyme data using BIosys (Swofford \& Selander, 1989). This method adjusts for sampling variation and does not require genotype frequencies. $R_{\mathrm{ST}}$ (Slatkin, 1995), a statistic related to $F_{\mathrm{ST}}$ developed specifically for microsatellite loci, accounts for sampling variation and especially for the different mutation process thought to occur in microsatellite loci (high mutation rate and partial dependence of the mutant allele size on the original allele size). Slatkin's method relies on the assumptions of no constraints on allele size and that the mutation process is similar across all allele sizes. Calculation of the repeat number for each allele was based on a known sequence, where the length of the regions flanking the repeated motif was subtracted from the total allele length, and the result was divided by the length of the repeat unit. The sizes of a few alleles at locus $33 C 1$ differed by an amount that was not equal to the size of a repeat (Fig. 1) and $R_{\mathrm{ST}}$ calculation proceeded based on the following assumptions, namely that these alleles were created by an insertion/deletion of one nucleotide that occurred outside the repeat region, allowing rounding of the repeat number to the nearest integer. These noncanonical alleles had low frequency, comprising together eight per cent in both populations, thus even if these assumptions were wrong, the effect would be small. Locus $2 A 1$ had a complex series of allele sizes (Fig. 1) resulting from several repeat motifs of different sizes. Calculation of $R_{\mathrm{ST}}$ for locus $2 A 1$ was based on the assumption of a closer relationship between alleles of similar size, and thus rounding was performed based on the smallest motif size ( 6 bases). However, as the effect of this procedure was not known, average $R_{\mathrm{ST}}$ values for the set of microsatellite loci were calculated with and without this locus (Table 4).

Significance of the $F_{\text {ST }}$ was evaluated based on a chi-square test of the contingency table of allele frequencies by populations, after pooling rare alleles such that expected cell counts would be higher than 2 , and no more than 20 per cent of the cell counts would be lower than 5 . Significance of the $R_{\mathrm{ST}}$ (and $R_{\mathrm{IS}}$ ) was evaluated based on an $F$-test in a nested ANOVA on the repeat number in a model including the individual and the population as factors (Slatkin, 1995). The average $R_{\mathrm{ST}}$ was calculated from the averages of the within-population and total variance components across loci. Estimates of $\mathrm{Nm}$ were derived from $F_{\mathrm{ST}}$ for two populations according to Slatkin (1995): $N m=1 / 4\left(1 / F_{\mathrm{ST}}-1\right) . N m$ was derived from $R_{\mathrm{ST}}$ by substituting $R_{\mathrm{ST}}$ for $F_{\mathrm{ST}}$. Calculations not available in BIOSYS were carried out by programs written in the SAS language (SAS Institute, 1990).

\section{Results}

Microsatellite loci were highly polymorphic in both populations, with an average of 7.8 alleles (ranges of 2-13) per locus per population. The average unbiased heterozygosity was 0.63 (range of
Fig. 1 Allele composition at microsatellite loci in East and West African Anopheles gambiae.
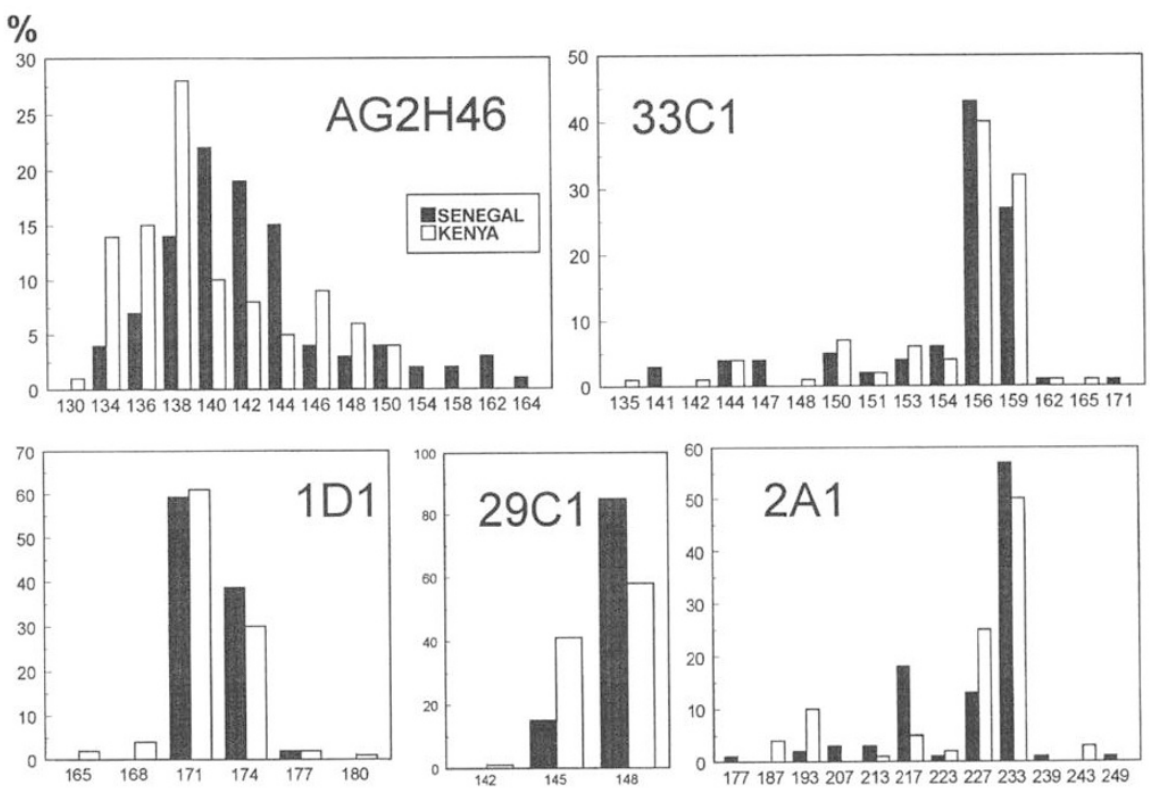

Allele length bp

(c) The Genetical Society of Great Britain, Heredity, 77, 192-208. 
0.26-0.87, Table 2 and Fig. 1). Allozyme loci were moderately polymorphic with an average of 3.2 alleles (between 1 and 6) per locus, and the average unbiased heterozygosity was 0.38 (range of $0.0-0.76$ ) (Table 2 and Fig. 2). Although the average unbiased heterozygosities of both microsatellite and allozyme loci were slightly higher in East Africa, the differences were not significant (signed rank paired test by locus $=15$, d.f. $=10, P>0.21$ and Table 3 ), suggesting no large difference in effective population sizes

Table 2 Polymorphism of microsatellite and allozyme loci in populations of Anopheles gambiae from Kenya and Senegambia

\begin{tabular}{|c|c|c|c|c|c|c|c|c|c|c|}
\hline \multirow[b]{2}{*}{ Locus } & \multicolumn{5}{|c|}{ Kenya* } & \multicolumn{5}{|c|}{ Senegambia* } \\
\hline & $N$ & $\begin{array}{l}\text { No. of } \\
\text { alleles }\end{array}$ & $\begin{array}{l}\text { Common } \\
\text { allele } \%\end{array}$ & $H_{\mathrm{E}}^{\dagger}$ & $H_{\mathrm{O}} \ddagger$ & $N$ & $\begin{array}{l}\text { No. of } \\
\text { alleles }\end{array}$ & $\begin{array}{l}\text { Common } \\
\text { allele \% }\end{array}$ & $H_{\mathrm{E}}^{\dagger}$ & $H_{\mathrm{O}} \ddagger$ \\
\hline \multicolumn{11}{|c|}{ Microsatellites } \\
\hline$A G 2 H 46$ & 50 & 10 & 28 & 0.856 & 0.760 & 50 & 13 & 22 & 0.870 & 0.860 \\
\hline $33 C 1$ & 50 & 12 & 40 & 0.732 & 0.580 & 50 & 11 & 43 & 0.737 & 0.720 \\
\hline $29 \mathrm{Cl}$ & 50 & 3 & 58 & 0.500 & 0.480 & 50 & 2 & 85 & 0.258 & 0.260 \\
\hline $1 D 1$ & 50 & 6 & 61 & 0.541 & 0.500 & 49 & 3 & 59 & 0.504 & 0.449 \\
\hline $2 A 1$ & 50 & 8 & 50 & 0.679 & 0.640 & 50 & 10 & 57 & 0.629 & 0.640 \\
\hline Average & 50 & 7.8 & 47.4 & 0.662 & 0.592 & 49.8 & 7.8 & 53.2 & 0.600 & 0.586 \\
\hline \multicolumn{11}{|c|}{ Allozymes } \\
\hline EST-1 & 24 & 3 & 75 & 0.415 & - & 22 & 3 & 48 & 0.591 & - \\
\hline EST-2 & 24 & 3 & 50 & 0.550 & - & 22 & 4 & 68 & 0.481 & - \\
\hline EST-3 & 24 & 6 & 42 & 0.755 & - & 22 & 6 & 52 & 0.671 & - \\
\hline$O D H$ & 22 & 1 & 100 & 0.000 & - & 22 & 2 & 98 & 0.045 & - \\
\hline$P G M 1$ & 22 & 3 & 75 & 0.409 & - & 22 & 3 & 77 & 0.385 & - \\
\hline$P G M 2$ & 22 & 2 & 89 & 0.206 & - & 22 & 2 & 96 & 0.089 & - \\
\hline Average & 23 & 3.0 & 71.1 & 0.389 & - & 22 & 3.3 & 87.8 & 0.377 & - \\
\hline
\end{tabular}

*For microsatellites, the Kenyan population was obtained from Asembo Bay and the Senegalian population from Barkedji; for allozymes (Miles, 1978), the Kenyan population was obtained from Chulaimbo and the Gambian population from Mandinari.

†Unbiased heterozygosity (Nei, 1978).

$\ddagger$ Observed heterozygosity based on direct count of heterozygotes.


Allele state

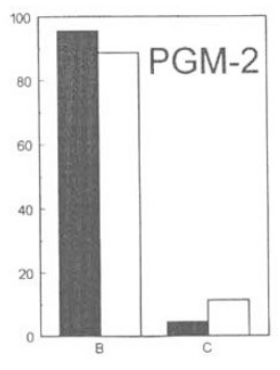

Fig. 2 Allele composition at allozyme loci in East and West African Anopheles gambiae. 
between these populations from East and West Africa. The heterozygosity of microsatellite loci, however, was significantly higher than that of allozymes (Table 3). This difference was expected, based on known higher mutation rates reported for microsatellite loci (e.g. Dallas, 1992; Weber \& Wong, 1993).

Deviations from Hardy-Weinberg expectations were not significant $(P>0.05)$ for all microsatellite loci in both populations (data not shown). Similarly, the within-individual variance component of the number of repeats tested by nested ANOVA (Slatkin, 1995) was not significant for all loci (data not shown). No evidence was obtained for nonrandom mating in the populations.

The allele compositions of both microsatellite and allozyme loci were very similar between West and East Africa (Figs 1 and 2). Every allele with a frequency higher than five per cent in a given population was also found in the other population, and the most common allele was the same in both popu-

Table 3 The differences in locus unbiased heterozygosity $\left(H_{\mathrm{E}}\right)$ between genetic markers and locales (as indicators of $N_{\mathrm{e}}$ ): ANOVA results

\begin{tabular}{lrcc}
\hline Source & d.f. & Mean square & $P$ \\
\hline Model* $^{*}$ & 2 & 0.170 & 0.060 \\
Error & 19 & 0.052 & - \\
Genetic marker & 1 & 0.334 & 0.020 \\
Population & 1 & 0.007 & 0.724 \\
\hline
\end{tabular}

Model $R^{2}=26 \%$.

See Table 2 for group means.

*Interaction term was removed after it was found to be not significant when included $(P>0.8)$. lations for four of the five microsatellite loci (Fig. 1) and four of the six allozyme loci (Fig. 2). Differentiations of the populations, as measured by $F_{\text {ST }}$ and $R_{\mathrm{ST}}$ were accordingly low $(0.0-0.09$, Table 4$)$ and all $N m$ values were larger than 1 . The $R_{\mathrm{ST}}$ values of microsatellite loci were higher than their corresponding $F_{\text {ST }}$ (except for locus $2 A 1$, see Materials and methods), as expected of loci with high mutation rates, and with high likelihood that the same allele could be produced by independent mutations (Slatkin, 1995). Nevertheless, the $R_{\mathrm{ST}}$ (and $F_{\mathrm{ST}}$ ) values of $A G 2 H 46$ and $29 C 1$ were significant, whereas only the $F_{\mathrm{ST}}$ but not the $R_{\mathrm{ST}}$ of locus $2 A 1$ was significant (Table 4). Likewise, the $F_{\mathrm{ST}}$ values of two of the six allozyme loci were significant.

\section{Discussion}

A remarkable similarity in allele profile of $A$. gambiae populations $6000 \mathrm{~km}$ apart was evident at microsatellite and allozyme loci. The significance of the divergence indices in two (or three if $F_{\mathrm{ST}}$ is used) of the five microsatellite loci and in two of the six allozyme loci implies that a degree of separation between the gene pools does exist. However, low estimates of interpopulation differentiation were measured by Wright's $F_{\mathrm{ST}}$ and Slatkin's $R_{\mathrm{ST}}$, corresponding to high estimates of the average migration index $(N m>3)$ across this enormous distance. Genetic differentiation at 'neutral' loci because of genetic drift is expected if $N m<1$ but not if $N m>1$ (Slatkin, 1987). The consistency of the differentiation indices across loci, i.e. all 11 estimates fall in a narrow range of $0-0.087$, implies that heterogeneity among loci in each marker group was not large. Accordingly, considering the three loci with the

Table 4 Differences between Anopheles gambiae populations from Kenya and Senegambia based on microsatellite and allozyme loci

\begin{tabular}{|c|c|c|c|c|}
\hline \multicolumn{3}{|c|}{ Microsatellites } & \multicolumn{2}{|c|}{ Allozymes } \\
\hline Locus $\left(N_{\mathrm{k}}, N_{\mathrm{s}}\right) \dagger$ & Wright's $F_{\text {ST }}(N m)$ & Slatkin's $R_{\mathrm{ST}}(\mathrm{Nm})$ & Locus $\left(N_{\mathrm{g}}, N_{\mathrm{k}}\right)$ & Wright's $F_{\mathrm{ST}}(\mathrm{Nm})$ \\
\hline$A G 2 H 46(50,50)$ & $0.013^{* *}(9.5)$ & $0.0624^{* * *}(1.9)$ & EST-1 $(22,24)$ & $0.087^{* * *}(1.3)$ \\
\hline $33 C 1(50,50)$ & $0.0 \mathrm{NS}(\gg 1)$ & $0.0000 \mathrm{NS}(\gg 1)$ & EST-2 $(22,24)$ & $0.018 \mathrm{NS}(6.8)$ \\
\hline $29 C 1(50,50)$ & $0.077^{* * *}(1.5)$ & $0.08620 * * *(1.3)$ & EST-3 $(22,24)$ & $0.037^{* *}(3.3)$ \\
\hline IDI $(50,49)$ & $0.0 \mathrm{NS}(\gg 1)$ & 0.0097 NS (12.7) & $O D H(22,22)$ & $0.0 \mathrm{NS}(\gg 1)$ \\
\hline \multirow[t]{2}{*}{$2 A 1(50,50)$} & \multirow[t]{2}{*}{$0.01^{* *}(12.4)$} & \multirow[t]{2}{*}{0.0029 NS (42.5) } & PGM-1 $(22,22)$ & $0.0 \mathrm{NS}(\gg 1)$ \\
\hline & & & $P G M-2(22,22)$ & $0.0 \mathrm{NS}(\gg 1)$ \\
\hline Average 5 loci & $0.016(7.7)$ & $0.0358(3.4)$ & Average & $0.036(3.3)$ \\
\hline 4 loci & & $0.0469(2.5)$ & & \\
\hline
\end{tabular}

† Sample size (mosquitoes): $N_{\mathrm{k}}$, Kenya; $N_{\mathrm{s}}$, Senegal; and $N_{\mathrm{g}}$, Gambia.

NS $P>0.05,{ }^{* *} P<0.01,{ }^{* * *} P<0.001$.

(c) The Genetical Society of Great Britain, Heredity, 77, 192-208. 
highest differentiation estimates from each group increased the average $R_{\mathrm{ST}}$ of microsatellite loci to 0.061 (corresponding to an $N m=1.9$ ) and the average divergence of allozymes to only 0.047 (corresponding to an $N m=2.5$ ). Thus, even these estimates imply extensive gene flow across the continent. Furthermore, regional analyses of Miles's (1978) six-loci data including either 10 or six localities divided into West (Gambia), East (Kenya and Tanzania), and Central Africa (Nigeria and Cameroon) with samples larger than 12 or 20 mosquitoes, respectively, provided slightly lower estimates of between-region $F_{\mathrm{ST}}(0.015$ and 0.021 , data not shown).

For comparison, microsatellite loci in the honey bee, Apis mellifera, measured far greater divergence between populations within lineages, with an average $F_{\text {ST }}$ value of 0.34 (Estoup et al., 1995), whereas allozyme variation hardly exists. Pairwise average $F_{\mathrm{ST}}$ values for populations within the least differentiated honey bee subspecies, separated by less than 2500 and $2000 \mathrm{~km}$ (two from France and one from Sweden), were 0.083 and 0.042 , respectively, vs. 0.016 in the populations of the present study (Table 4). The mosquito Aedes aegypti showed a complex structure with substantial differentiation on a worldwide scale (Powell et al., 1980), although extensive gene flow $(\mathrm{Nm}>9)$ was observed across approx. $150 \mathrm{~km}$ in Puerto Rico (Apostol et al., 1995). Even greater geographical differentiation was observed in Aedes albopictus in Malaysia and Borneo (Black et al., 1988).

Because mark-release-recapture experiments have suggested that active dispersal in $A$. gambiae is restricted to a few kilometers (Gillies \& De Meillon, 1968), it is unlikely that active dispersal accounts for the low differentiation. An alternative explanation is that $A$. gambiae, a highly domestic mosquito, has expanded to its current range in recent evolutionary time in response to the major expansion in human population density that followed the development of agriculture in West Africa about 2000-5000 years ago (Coluzzi et al., 1985). It is conceivable that with population expansion occurring within the past few thousand years and with large effective population size, the divergence of populations across the African continent could remain low today.

The similarity of estimates of divergence measured by marker systems so different in their timescale resolution is surprising. Microsatellite loci evolve considerably faster than allozyme loci, and have mutation rates of $10^{-3}-10^{-4}$ per locus per gamete per generation (Dallas, 1992; Weber \& Wong, 1993) vs. $10^{-6}-10^{-9}$ for allozyme loci (Ayala,
1976). Thus they are expected to detect differentiation between populations that occurred over shorter periods. The lower polymorphism of the allozymes as compared with the microsatellite loci (Tables 2 and 3 ) is consistent with the mutation rates of the microsatellite loci being higher than those of the allozyme loci. In spite of mutation rates at least one scale order higher than that of allozymes, the $R_{\mathrm{ST}}$ estimate for the microsatellite loci was not higher than the $F_{\mathrm{ST}}$ for the allozymes. The failure of microsatellite loci to detect greater divergence than allozyme loci suggests the existence of constraints on their evolution, such as biased mutation rates (Garza et al., 1995) and/or selection for certain allele sizes (Epplen et al., 1993).

Alternatively, dispersal via both active and passive transportation of $A$. gambiae during the past century might be much higher than generally appreciated. Surprisingly high numbers of $A$. gambiae have been captured in trains and boats in Africa (Holstein, 1954). The rapid geographical spread of this mosquito after its introduction into Brazil in 1930 also indicates considerably higher rates of dispersal than commonly appreciated. The spread of $A$. gambiae in Brazil from its point of introduction in 1930 to the extreme extent of its range in 1938-40 was at an average minimal rate of $50 \mathrm{~km} \mathrm{y}^{-1}$, based on Soper \& Wilson (1943). This is probably an underestimate because (1) it is based on the detection of new, fully established populations rather than small numbers of migrants, (2) the estimate assumes a constant rate of movement over the entire 10 -year period, and (3) populations could successfully spread only in the north-westerly direction. If migration at such a rate is also occurring in Africa, it may be sufficient to explain the low levels of genetic divergence between populations in East and West Africa. Furthermore, such high rates of migration would also explain our finding of similar estimates of divergence obtained by the two different marker systems, without the need to invoke constraints on their evolution.

The low levels of genetic differentiation between populations from East and West Africa would seem to be incompatible with the very high levels of chromosomal-inversion-based genetic population structure recorded in $A$. gambiae populations, particularly from West Africa (Coluzzi et al., 1985; Lanzaro et al., 1995). Several distinct chromosomal forms and a series of climato-geographically stable clines in the frequencies of certain chromosomal inversions are characteristic of many populations in West Africa, whereas they have not been found in East Africa despite extensive karyotype data from 
Kenya and Tanzania. These reports of highly structured West African populations might suggest restricted gene flow in sympatric populations across dimensions other than geographical distance - the only dimension explored in this study. It is important to note that the Savanna chromosomal form is the only form known to occur in Kenya (Coluzzi et al., 1985) and Barkedji (Fontenille, unpublished data). Additionally, the strong selection operating on many of these chromosomal inversions that is evident by regular seasonal or spatial-climatological change in karyotype frequencies may render them unsuitable for gene flow evaluations.

At this point there is insufficient information to explain the low differentiation of $A$. gambiae populations across Africa by ruling out either the hypothesis of recent expansion, which is coupled with constraints on microsatellite evolution, or the hypothesis of migration augmented by transportation. Information based on additional genetic loci, different genetic markers, and populations on microand macrogeographical scales is necessary before final conclusions can be reached.

\section{Acknowledgements}

We are grateful to William C. Black IV, Nora J. Besansky, and Michel Tibayrenc for valuable suggestions throughout this study and useful comments on earlier versions of this manuscript. We thank Brian Holloway and staff of the NCID Biotechnology Core Facility for synthesizing the oligonucleotide primers and Diane M. Hamm for valuable advice on the laboratory work. T.L. was supported by an American Society for Microbiology Fellowship. Additional financial support was provided by the John D. and Catherine T. MacArthur Foundation and by the UNDP/WORLD BANK/WHO Special Programme for Research and Training in Tropical Diseases.

\section{References}

APOSTOL, B. L., BLACK, w. C., IV., REITER, P. AND MILLER, B. R. 1995. Population genetics with RAPD-PCR markers: the breeding structure of Aedes aegypti in Puerto Rico. J. Med. Entomol., (in press).

AyAlA, F. J. (ed.) 1976. Molecular Evolution. Sinauer Associates, Sunderland, MA.

BEARD, C. B., HAMM, D. M. AND COLlLINS, F. H. 1993. The mitochondrial genome of the mosquito Anopheles gambiae: DNA sequence, genome organization, and comparisons with mitochondrial sequences of other insects. Insect Mol. Biol., 2, 103-124.

BESANSKY, N. J., BEDELL, J. A., BENEDICT, M. Q., MUKA-
BAYIRE, O., HILFIKER, D. AND COLLINS, F. H. 1995. Cloning and characterization of the white gene from Anopheles gambiae. Insect Mol. Biol., 4, 217-231.

BLACK, W. C., IV, HAWLEY, W. A., RAI, K. S. AND CRAIG, G. B., Jr. 1988. Breeding structure of a colonizing species: Aedes albopictus (Skuse) in peninsular Malaysia and Borneo. Heredity, 61, 439-446.

BOWCOCK, A. M., RUIZ-LINARES, A., TOMFOHRDE, J., MINCH, E., KIDD, J. R. AND CAVAlli-SFORZA, L. L. 1994. High resolution of human evolutionary trees with polymorphic microsatellites. Nature, 368, 455-457.

COLlins, F. H. AND BESANSKY, N. J. 1994. Vector biology and control of malaria in Africa. Science, 264, $1874-1875$.

COLLINS, F. H., MENDEZ, M. A., RASMUSSEN, M. O., MEHAFFEY, P. C., BEASANSKY, N. J. AND FINNERTY, v. 1987. A ribosomal RNA gene probe differentiates member species of Anopheles gambiae complex. Am. J. Trop. Med. Hyg., 37, 37-41.

COLUZZI, M., PETRARCA, V. AND DI DECO, M. 1985. Chromosomal inversion intergradation and incipient speciation in Anopheles gambiae. Boll. Zool., 52, 45-63.

CRAMPTON, J. M., WARREN, A., LYCETT, G. J., HUGHES, M. A., COMLEY, I. P. AND EGGLESTON, P. 1994. Genetic manipulation of insect vectors as a strategy for the control of vector-borne disease. Ann. Trop. Med. Parasitol., 88, 3-12.

DALLAS, J. F. 1992. Estimation of microsatellite mutation rates in recombinant inbred strains of mouse. Mamm. Genome, 3, 452-456.

DI RIENZO, A., PETERSON, A. C., GARZA, J. C., VALDES, A. M., SLATKIN M. AND FREIMER, N. B. 1994. Mutational processes of simple-sequence repeat loci in human populations. Proc. Natl. Acad. Sci. U.S.A., 91, 3166-3170.

EDWARDS, A., HAMMOND, H. A., JIN, L., CASKEY, C. T. AND CHAKRABORTY, R. 1992. Genetic variation of five trimeric and tetrameric tandem repeat loci in four human population groups. Genomics, 12, 241-253.

EPPLEN, C., MELMER, G., SIEDLACZCK, I., SCHWAIGER, F.-W., MÄUELER, W. AND EPPLEN, J. T. 1993. On the essence of "meaningless" simple repetitive DNA in eukaryote genomes. In: Pena, S. D. J., Chakraborty, R., Epplen, J. T., and Jeffreys, A. J. (eds) DNA Fingerprinting: State of the Science, pp. 29-45. Birkhauser Verlag, Basel.

ESTOUP, A., GARNERY, L. SOLIGNAC, M. AND CORNUET, J.-M. 1995. Microsatellite variation in honey bee (Apis mellifera L.) populations: hierarchical genetic structure and test of the infinite allele and stepwise mutation models. Genetics, 140, 679-695.

FITZSIMMONS, N. N., MORITZ, c. AND MOORE, s. S. 1995. Conservation and dynamics of microsatellite loci over 300 million years of marine turtle evolution. $\mathrm{Mol}$. Biol. Evol., 12, 432-440.

GARZA, J. C., SLATKIN, M. AND FREIMER, N. B. 1995. Microsatellite allele frequencies in humans and chimpanzees, with implications for constraints on allele size. Mol. Biol. Evol., 12, 594-603.

Gillies, M. T. AND DE meillon, B. 1968. The Anophelinae 
of Africa South of the Sahara, 2nd edn. Publications of the South African Institute for Medical Research no. 54. Johannesburg, South Africa.

HOLSTEIN, M. H. 1954. Biology of Anopheles gambiae, Research in French West Africa. WHO, Geneva.

KUMAR, V. K. AND COllins, F. H. 1993. A technique for nucleic acid in situ hybridization to polytene chromosomes of mosquitoes in the Anopheles gambiae complex. Insect Mol. Biol., 3, 41-47.

LANZARO, G. C., TOURE, Y. T., ZHENG, L., KAFATOS, F. C. AND VERNICK, K. D. 1995. Microsatellite DNA and isozyme variability in a West African population of Anopheles gambiae. Insect Mol. Biol., 4, 105-112.

MILEs, s. J. 1978. Enzyme variation in the Anopheles gambiae Giles group of species (Diptera: Culicidae). Bull. ent. Res., 68, 85-96.

NEI, M. 1978. Estimation of average heterozygosity and genetic distance from a small number of individuals. Genetics, 89, 583-590.

POWELl, J. R., TABACHNICK, W. J. AND ARNOLD, J. 1980. Genetics and the origin of a vector population: Aedes aegypti, a case study. Science, 208, 1385-1387.

SALAZAR, C. E., HAMM, D. M., WESSON, D. M., KUMAR, V. K., BEARD, C. B. AND COLlins, F. H. 1993. A cytoskeletal actin gene in the malaria vector Anopheles gambiae. Insect Mol. Biol., 3, 1-14.

SAMBROOK, J., FRITSCH, E. F. AND MANIATIS, T. 1989. Molecular Cloning, a Laboratory Manual, 2nd edn. Cold
Spring Harbor Laboratory Press, NY.

SAS INSTITUTE INC. 1990. SAS language: references. Version 6, 1st edn. Cary, NC.

SCOTT, J. A., BROGDON, w. G. AND COLlins, F. H. 1993. Identification of single specimens of the Anopheles gambiae complex by the polymerase chain reaction. Am. J. Trop. Med. Hyg., 49, 520-529.

SLATKIN, M. 1987. Gene flow and the geographical structure of natural populations. Science, 236, 787-792.

SLATKIN, M. 1995. A measure of population subdivision based on microsatellite allele frequencies. Genetics, 139, $457-462$.

SOPER, F. L. AND WILSON, D. B. 1943. Anopheles gambiae in Brazil 1930-1940. Rockefeller Foundation, New York.

SWOFFORD, D. L. AND SELANDER, R. B. 1989. BIOSYS-1. $A$ Computer Program for the Analysis of Allelic Variation in Population Genetics and Biochemical Systematics. Release 1.7. University of Illinois, Urbana, IL.

WEBER, J. L. AND WONG, C. 1993. Mutation of human short tandem repeats. Hum. Mol. Genet., 2, 1123-1128.

WRight, s. 1978. Evolution and the Genetics of Populations, vol. 4, Variability Within and Among Natural Populations. University of Chicago Press, Chicago.

ZHENG, L., SOUNDERS, R. D. C., FORTINI, D., TORRE, A. D., COLUZZI, M., Glober, D. M. AND KAFATOS, F. C. 1991. Low-resolution genome map of the malaria mosquito Anopheles gambiae. Proc. Natl. Acad. Sci. U.S.A., 88, 11187-11191. 